\title{
O PARADOXO DA AVALIAÇÃO INSTITUCIONAL DA UNIVERSIDADE NO BRASIL
}

\author{
Prof. Ms. Cesar CANDIOTTO*
}

\section{Resumo}

O artigo em questão pretende mostrar o vínculo entre educação e desenvolvimento no âmbito das políticas governamentais de avaliação institucional das universidades no Brasil. Busca-se mostrar que tais políticas tendem a adotar o conceito de qualidade total próprio da gestão empresarial. Entretanto, para o autor, a qualidade da universidade pública não pode ser medida pela eficiência/produtividade equacionada pela relação custos/benefícios. Antes, por ser uma instituição pública, a universidade deve preocupar-se sim com a produção do saber e com a qualidade sócio-política, pois seu objetivo não é o lucro e sim atender as demandas por uma educação melhor e uma sociedade mais democrática.

Palavras-chave: Universidade Pública - Avaliação Institucional - Qualidade Total.

\section{Resumen}

Este artículo muestra la relación entre educación y desarrollo, con énfasis en las políticas gubernamentales de evalución de las universidades en Brasil. Estas políticas tienden a la adopción del concepto de calidad total específico del sector empresarial. No obstante, el autor desea demostrar que no se puede solamente mensurar la calidad de la Universidad oficial por la relación costos/ganancias. Más bien, siendo una institución pública, la universidad debe preocuparse con la producción del saber y con la calidad sociopolítica, considerando que su reto no es la rentabilidad, sino la búsqueda de una mejor educación y una sociedad más democrática.

Palabras llave: Universidad Oficial - Evaluación Institucional - Calidad Total.

* Mestre em Educação pela PUCPR e Doutorando em Filosofia pela PUCSP. Professor do Curso de Filosofia da PUCPR. 


\section{Introdução}

A avaliação institucional da universidade é um dos temas mais urgentes a ser discutido no âmbito das políticas educacionais no Brasil, principalmente, no que concerne às universidades oficiais. $\mathrm{O}$ motivo é claro: se, por um lado a política governamental tem se concentrado na descentralização dos recursos no financiamento das Instituições Federais de Ensino Superior, por outro, adota, paradoxalmente, uma política de centralização por meio da avaliação de desempenho e de resultados (Lei 9.131/95). Assim, descentraliza-se 0 financiamento, mas centraliza-se o controle.

O presente estudo pretende esclarecer em que medida tal estratégia faz parte das contingências da política educacional para o Ensino Superior no Brasil; e, em que medida, trata-se de um reflexo da própria reorganização produtiva do capitalismo internacional por meio de seus organismos multilaterais. Ainda, pretende mostrar que no caso do Brasil tem predominado uma avaliação de resultados. A avaliação de resultados serve como controle da qualidade acadêmica, mas principalmente como controle da correlação custos-benefícios. Adotando critérios homogêneos, investe-se mais naquelas universidades que têm tradição em ensino e pesquisa já consolidada; por conseqüência, investe-se pouco naquelas que têm pouco potencial por estarem ainda em processo de constituição.

\section{Do contex to do surgimento da ava liação universitá ria a té a lei 9.131/95: o ex a me nacional de cursos}

A origem do processo de avaliação institucional das universidades brasileiras iniciou-se já no final dos anos 50 e nos anos 60, culminando com a Reforma Universitária em 1968. Nesse período, houve uma avaliação assistemática das universidades acerca de seu papel na mobilidade social a partir das reformas de base da sociedade daquele momento.

No entanto, o fim do nacional-desenvolvimentismo no Brasil e a reorientação da economia pelo Golpe Militar afetaram em termos políticoinstitucionais as ricas avaliações assistemáticas das universidades. Com 0 imperativo de modernizar o país, ampliou-se o acesso ao ensino superior impondo a "racionalização das atividades universitárias para a obtenção de maior eficiência e produtividade" (SGUISSARDI, 1997, p. 47).

A partir de 1985, não obstante a abertura política, inicia-se uma nova tentativa de avaliação universitária por meio do documento Uma Nova Política para a Edu cação Superior, pelas denominadas Comissões de Alto Nível (GERES: Grupo Executivo para a Reformulação do Ensino Superior) e Comissão Nacional para a Reformulação da Educação Superior) (CARDOSO, 1989a, p. 
9). Embora o contexto político do momento tivesse como marco a redemocratização, sem embargo, a orientação de tal avaliação foi extremamente centralizada. Isso porque privilegiou-se a lógica da eficiência e legislou-se a partir do alto, ignorando o caráter democrático próprio de qualquer avaliação institucional.

Já entre 1992 e 1994, a comunidade universitária, juntamente com o MEC, então presidido pelo ministro Murílio de Avellar Hingel, empreenderam iniciativas conjuntas significativas na tentativa de reformular critérios de avaliação institucional que respeitassem a pertinência histónica de cada universidade e a melhoria de sua qualidade institucional.

Tais iniciativas foram consolidadas com a criação do Programa de Avaliação Institucional das Universidades Brasileiras (PAIUB), em 1994. As características básicas do PAIUB fundamentam-se em sete princípios: 1) globalidade; 2) comparabilidade; 3) respeito à identidade institucional; 4) não premiação ou punição; 5) adesão voluntária; 6) legitimidade; 7) continuidade (RISTOFF, 1994, p. 8-11).

O princípio da globalidade propõe que não se deve avaliar a universidade apenas a partir de uma de suas atividades. "O ensino, a pesquisa, a extensão, a administração, a qualidade das aulas, dos laboratórios, a titulação do corpo docente, a biblioteca, os registros escolares, as livrarias universitárias, os serviços, a organização do poder, o ambiente físico, o espírito e as tendências da vida acadêmica, enfim, todos os elementos que compõem a vida universitária devem fazer parte da avaliação para que a mesma seja a mais completa possível" (RISTOFF, 1994, p. 8). O princípio da comparabilidade não tem como pretexto o estabelecimento de rankings entre as universidades, mas "a busca de um linguajar comum dentro da universidade e entre as universidades" (p. 8).

O princípio da identidade institucional tem como escopo evitar a homogeneização dos critérios de avaliação e a consideração da pertinência histórica de cada instituição, levando em conta sua heterogeneidade. Segundo DIAS SOBRINHO (1998, p. 6), "A referência principal da avaliação é a missão de cada instituição e as maneiras de esta cumprir os seus compromissos sociais. Portanto, para além dos aspectos gerais e universais da avaliação, cada universidade deve definir com clareza os princípios e objetivos mais apropriados ao seu processo, bem como as melhores e mais adequadas maneiras de realizá-lo, não perdendo de vista a identidade (dinâmica) institucional". O princípio da não-punição ou premiação se justifica, pois vive-se num país que premia pouco e interfere muito na vida privada do cidadão. RISTOFF (1994, p. 9) observa que nas avaliações têm predominado as punições e, por isso, a premiação ou punição não deve entrar na avaliação universitária. $\mathrm{O}$ que se deve propiciar é uma cultura da avaliação, e isso só se dará pelo princípio da adesão voluntária de cada universidade. "E este processo só logrará êxito se 
for coletivamente construído e se puder contar com intensa participação de seus membros, tan to nos procedimentos e implementação, como na utilização dos resultados." (RISTOFF, 1994, p.10-11). Já a legitimidade se expressa de duas maneiras: "(1) numa metodologia capaz de garantir a construção de indicadores adequados, acompanhados de uma abordagem analítico-interpretativa capaz de dar significado às informações; e (2) na construção de informações fidedignas, em espaço de tempo capaz de ser absorvido pela comunidade universitária" (p. 11). Finalmente, o princípio da continuidade possibilita a comparabilidade dos dados em momentos diferentes para avaliar sua eficácia. A reavaliação deve ser realizada depois da avaliação externa.

Entretanto, a partir de 1995, com a Reforma do Estado brasileiro impulsionada pelo governo de Cardoso, a avaliação do desempenho universitário recobra força. O ministro Murílio de Avellar Hingel é substituído pelo ministro Paulo Renato de Souza. O Ministério da Educação e do Desporto aprova a avaliação de resultados por meio do Exame Nacional de Cursos, aplicável tanto nas universidades públicas quanto nas universidades privadas.

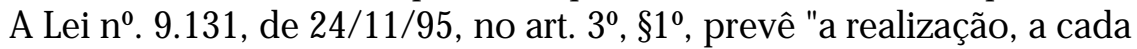
ano, de exames nacionais com base nos conteúdos mínimos estabelecidos para cada curso, previamente divulgados e destinados a aferir os conhecimentos e competências adquiridos pelos alunos em fase de conclusão dos cursos de graduação".

Já no art. 3o lê-se: "o Ministério da Educação e do Desporto fará realizar avaliações periódicas das instituições e dos cursos de nível superior, fazendo uso de procedimentos e critérios abrangentes dos diversos fatores que determinam a qualidade e a eficiência das atividades de ensino, pesquisa e extensão" (grifos nossos).

A lei é clara quando menciona que, pelos exames nacionais de cursos, serão avaliadas as próprias instituições. Isto envolve também a avaliação da infra-estrutura, da titulação docente e do projeto pedagógico de cada instituição.

Entretanto, o que mais interessa são os critérios e procedimentos pelos quais tal avaliação se realiza. Eles se concentram nos "diversos fatores que determinam a qualidade e a eficiência das atividades de ensino, pesquisa e extensão". Só é possível elaborar uma hermenêutica adequada do texto e suas conseqüências para as Instituições Federais de Ensino Superior se os termos "qualidade e eficiência" forem situados no contexto histórico de tal Lei.

O contexto da avaliação de resultados na política do governo após 1995 obedece ao imperativo da inserção dos países periféricos - caso do Brasil - na globalização. Tal avaliação visa, sobretudo, a desvincular as universidades oficiais do núcleo burocrático do Estado e aproximá-las do setor produtivo.

Diante do argumento de que as universidades oficiais só servem para 
a classe alta e diante do descrédito da instituição universitária (SANTOS, 1996) emergem as exigências da qualidade medida pela eficiência/produtividade. Ou seja, a "qualidade e a eficiência" de que se trata aqui refere-se às novas roupagens da teoria do capital humano. A base do discurso é que, para serem eficientes, as universidades oficiais devem ter autonomia financeira, não dependendo do financiamento exclusivo do Estado, mas da busca de recursos no setor privado. Porquanto a autonomia, no novo discurso, equivale à progressiva privatização e à racionalização. E a eficiência, no investimento privado, está atrelada à produtividade e à qualidade total.

No art. $3^{\circ}, 1^{\circ}$, lê-se que tais procedimentos incluirão "a realização, a cada ano, de exames nacionais com base nos conteúdos mínimos estabelecidos para cada curso, previamente divulgados e destinados a aferir os conhecimentos e competências adquiridas pelos alunos em fase de conclusão de cursos de graduação".

Diante deste procedimento avaliativo, caberia inquirir se o mesmo não se constitui numa nova modalidade de vestibular ao final de cada curso de graduação. Se são submetidos à avaliação apenas os "conteúdos mínimos" (os resultados) de cada curso, mas não o processo em si, não se estaria favorecendo o surgimento de novos cursinhos no interior das universidades para preparar os alunos para o Exame? E, deste modo, não se estaria utilizando-se de um paliativo para preservar os cursos do descredenciamento, mas sem que o processo mudasse efetivamente?

O resultado das avaliações será divulgado anualmente pelo Ministério da Educação, informando o "desempenho" de cada curso, sem identificar nominalmente os alunos avaliados (art. $3^{\underline{0}}, \S 2^{\underline{o}}$ ). Embora os resultados não sejam divulgados nominalmente, o fato de que o curso avaliado em determinada universidade obtenha nota A ou D interferirá na absorção do aluno de tal curso no mercado de trabalho. Já que a avaliação é meritocrática, não seria mais justo divulgar os resultados nominalmente, para identificar os futuros bons profissionais daqueles que têm por único objetivo a obtenção do diploma?

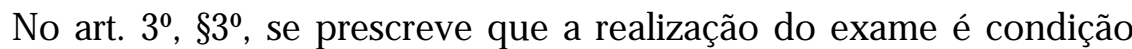
prévia para obtenção do diploma e sua realização constará do diploma, embora o resultado individual não seja condição para sua aprovação ( $\left.\$ 4^{\circ}{ }^{\circ}\right)$. Ou seja, o curso poderá ser descredenciado, mas o aluno terá o seu diploma mesmo que tenha reprovado em tal exame. O Ministério da Educação transfere a avaliação da capacidade técnica do profissional para o mercado de trabalho.

Já no art. 4ํㅡ, explica-se que os resultados das avaliações servirão para o Ministério da Educação "estimular e fomentar iniciativas voltadas para a melhoria da qualidade do ensino, principalmente as que visem à elevação da qualificação dos docentes" (grifos nossos). Portanto, o Ministério associa a melhoria da qualidade de ensino à elevação da qualificação docente. Esta é 
entendida pelo Ministério como titulação stricto sensu, ou seja, iniciativas que visem a aumentar os programas de mestrado e doutorado; a qualificação também é medida pelo número de publicações, participação em simpósios, etc. Entretanto, diante das exigências da LDB 9.394/96 de "um terço do corpo docente, pelo menos, com titulação acadêmica de mestrado ou doutorado" (art. 52, inciso II), torna-se incompatível a pretensão da qualificação docente exigida pelo Ministério na proposta da avaliação docente.

Percebe-se pelo exposto que a discussão em torno da qualidade universitária é um tema que merece toda consideração, principalmente num período de profundas transformações na relação entre educação e produtividade, como tem sido o caso do Brasil no final do século XX até a atualidade.

\section{0 discurso da qualidade na avaliação institucional}

Como o termo qualidade pode ser entendido a partir de seu condicionamento contextual? Se existe um consenso no discurso da avaliação institucional dos anos noventa, este consiste no objetivo da avaliação: a qualidade universitária. O discurso da avaliação institucional é então indissociável do discurso da qualidade universitária.

Entretanto, a diferença entre o discurso do Estado avaliativo e o da comunidade universitária reside no conceito de qualidade universitária, podendo ser entendida tanto por critérios histórico-democráticos como por critérios eficientistas/produtivistas. A avaliação pode ajudar tanto no aprimoramento da qualidade acadêmica e na busca de uma universidade produtora de saber crítico, como também pode servir para reproduzir o status quo fundamentado na lógica do capital.

MOROSINI \& LEITE (1997) ressaltam a predominância dessa última nos últimos anos: "Tem predominado, nestes últimos anos, a avaliação como mecanismo indiscutível de questionamento da qualidade universitária que, na maioria das vezes, se especifica na gestão de qualidade total. Em educação cria-se a pedagogia da qualidade, voltada à maximização institucional" ( $\mathrm{p}$. 127, grifos dos autores). É preciso, pois, distinguir com cautela entre uma e outra forma de avaliação: entre aquela inspirada na produção do saber e aquela inspirada na produtividade própria da Filosofia e da Pedagogia da Qualidade Total.

Conforme SGUISSARDI (1997, p. 44):

Distinguir as propostas e práticas de avaliação conducentes a uma universidade produtora de saber e crítica daquelas propostas e práticas tendentes a 'ampliar e tornar mais eficaz o funcionamento do sistema escolar (universitário) dinigido para a reprodução da ordem estabelecida e da ótica do capi- 
tal' - hoje em grande medida inspirados nos princípios traduzidos pela Filosofia da Qualidade Total - é uma tarefa urgente que se impõe aos que pretendem contribuir para a melhoria e democratização da universidade.

A Filosofia da Qualidade Total oriunda do setor empresarial toyotista japonês esteve e está muito presente nas propostas de avaliação do Ensino Superior. Só no mês de agosto de 1994, foram realizados diversos encontros e congressos com a finalidade de implantar a Qualidade Total no Ensino Superior. Entre os dias 12-14 de agosto de 1994, realizaram-se o II Congresso Brasileiro da Qualidade no Ensino Superior, o I Congresso Brasileiro de Gestão Universitária e o I Congresso Brasileiro de Avaliação Universitária. Além disso, no dia 11, foram realizados dois Cursos Pré-Congressos denominados Os Fundamentos da Qualidade Total nas Instituições de Ensino Superior eA Qualidade Total Universitária: Metodologia de Implantação. Todos os cursos foram realizados no Centro de Convenções Rebouças, em São Paulo-SP, promovidos pelo Instituto Brasileiro da Qualidade em Serviços (IBRAQS), com apoio científico de várias instituições do setor privado. Para SGUISSARDI (1997, p. 43), tanto as avaliações realizadas nos últimos quinze anos, imunes à Filosofia da Qualidade Total, quanto aquelas mais recentes, que adotam essa filosofia, têm uma mesma raiz: "o imperativo da modernização; a globalização da economia; a ciência, a tecnologia e a informação transformadas em forças produtivas; o fim do fordismo (como organização industrial e modelo de desenvolvimento); o advento do neotaylorismo; a reestruturação do Estado nos moldes da cartilha neoliberal".

Portanto, não se pode entender a análise da qualidade total somente como um processo restrito a uma obtusa política educacional no âmbito do Brasil. Na verdade, todo o processo que se está tentando compreender faz parte de um imperativo que consiste basicamente na reestruturação do capitalismo no final do século XX e início do século XXI. Entretanto, não se sabe ainda as reais possibilidades de tal imperativo, visto que já se detectam seus limites tanto nos países centrais quanto nos países periféricos.

\subsection{0 discurso da eficiência/produtividade}

O vínculo da universidade com o sistema produtivo já se encontra presente no Plano Qüinqüenal de 1975-1979. A universidade e os recursos humanos de que deveria dispor eram vistos a partir da ótica do capital humano necessário para o desenvolvimento do sistema produtivo. Para AMORIM (1992, p. 25), "avaliava-se que a universidade brasileira deveria ter as dimensões técnicas de uma fábrica que refinaria um produto tecnológico importado, por ter exatamente os recursos humanos especializados e treinados para este fim". A universidade deveria ser a base de sustentação do modelo tecnológico sofisticado que penetrava no Brasil. 
Por outro lado, diante da retomada de forças da sociedade civil, sobretudo depois das Diretas Já, o governo tenta conter a expansão da universidade pública. Sob o pressuposto de que a mesma é "ineficiente" e "ingovernável" (BELONI, 1982, p. 1) operam-se as estratégias governamentais do controle das Instituições Federais de Ensino Superior por meio da avaliação institucional, racionalizando recursos conforme os índices de desempenho.

SGUISSARDI (1997, p. 52-53) sintetiza:

Fica evidente, tanto pelos documentos oficiais mais importantes quanto por pronunciamentos dos titulares do MEC nos últimos 10 a 15 anos, que as propostas oficiais de avaliação se fundam invariavelmente, apesar da linguagem mais ou menos disfarçada, na idéia de eficiência, de produtividade, correspondente à con cepção neoliberal de modernização ou, simplesmente, à lógica do capital no desenvolvimento da sociedade contemporânea. $\mathrm{O}$ disfarce pode estar em pomposos slogans 'Uma Nova Política para a Educação Superior', 'Projeto para uma Nova Universidade', 'Educação para Todos' etc. (grifos nossos).

Por conseguinte, a lógica da eficiência/produtividade atrelada à avaliação da universidade oficial desvincula-se da democratização da instituição universitária. Isto porque a sociedade não é vista como um conjunto de cidadãos com direitos, mas como um "conjunto diferenciado de contribuintes com a idéia de que quem paga tem direito" (SGUISSARDI, 1997, p. 53).

Entretanto, a qualidade (institucional universitária) não pode ser entendida apenas a partir da racionalidade tecnocrática eficientista/produtivista própria da visão empresarial. A outra forma de avaliar as Instituições Federais de Ensino Superior pode ser a partir da racionalidade emancipatória. Tal racionalidade não está atrelada à perspectiva instrumental da universidade em relação à empresa. Pelo contrário, supõe que a universidade constitui-se num espaço democrático como instituição social (não como organização social) comprometida com a autonomia do saber crítico-reflexivo e com a produção do conhecimento científico-tecnológico.

CARDOSO (1991) destaca que, segundo a última perspectiva, importa não apenas a "mera produtividade como medida do desempenho de cada instituição, mas, diferentemente, toma como eixo norteador a capacidade de produção, intrinsecamente considerada, da instituição universitária. Trata-se menos de quanto se produz, a que velocidade e a que custo, mas principalmente do que se produz, certamente também considerando o tempo e o custo dessa produção" (p.19) (grifos nossos). Não se trata, assim, de eliminar a qualidade técnica presente na avaliação. Mas, "os dados da qualidade técnica devem ser utilizados para fortalecer a visão crítica e transformadora da avaliação" (AMORIM, 1992, p. 67). Por isso, supõe uma qualidade no sentido acadê- 
mico-crítico que integre ensino-pesquisa-extensão. Trata-se efetivamente de superar o quantitativismo e o produtivismo na avaliação da qualidade universitária.

Não obstante, se o Banco Mundial e o discurso governamental classificam as universidades oficiais como sendo onerosas e improdutivas, caberia indagar o que, de fato, seria produtivo na universidade e quando esta poderia ser considerada uma instituição produtiva. O que está então em questão é a idéia mesma de produtividade.

Para AMORIM (1992, p. 58), a produtividade é "a faculdade que uma determinada empresa tem para produzir um certo produto de forma eficiente e que seja rentável". O autor remete à diferença que existe no fluxo industrial de uma empresa entre o controle de qualidade e o controle de produção. Se o controle de qualidade tem o sentido de verificar os defeitos no exato momento em que a produção ocorre, já o controle de produção confunde-se com a necessidade de eficiência, de produtividade, pois se refere à quantidade de produtos e a prazos de produção.

AMORIM (1992) salienta que, se por um lado o controle de qualidade é muito complexo para ser aplicado à universidade, por outro, o controle da produção acadêmica é muito comum em se tratando da avaliação institucional. Assim, "a sua eficiência produtiva seria comprovada pelo controle quantitativo do que a instituição, individual ou coletivamente, de fato produziu. Ou seja, seria preciso então quantificar as pesquisas realizadas, o ensino desenvolvido, os outros trabalhos acadêmicos realizados em sala de aula, nos laboratórios; as dissertações e teses, os artigos publicados, para sabermos se a instituição realmente produziu, ou não" (AMORIN, 1992, p. 59). Ora, tal perspectiva reforça a instrumentalização do trabalho intelectual. No fundo, a idéia de produtividade atrelada à universidade serviria apenas como critério da distribuição de recursos financeiros pelo governo para aquelas universidades federais mais produtivas e o corte orçamentário para aquelas improdutivas. Portanto, o Estado tem uma nítida intenção política nessa instrumentalização, na medida em que interfere na autonomia das Instituições Federais de Ensino Superior, controlando o trabalho intelectual por meio das elites dirigentes e descomprometendo-se financeiramente com aquelas instituições ou áreas do saber consideradas improdutivas.

Na lógica neoliberal, a ciência considerada produtiva é aquela que atende às necessidades das empresas, portanto, do capital. A partir do critério da produtividade, interessa mais o conhecimento que for mais rentável, que implique menos custos e mais benefícios. Deste modo, a ótica da produtividade atende às necessidades da minoria, e não da maioria.

Nesse sentido, AMORIM (1992, p. 61) se pergunta: "qual prática educativa pode ser concebida como produtiva, aquela construída pelos nossos educadores e educandos em suas relações sociais de produção do conhe- 
cimento crítico ou aquela imposta de cima para baixo e idealizada pelas nossas elites dirigentes?" Se o conhecimento construído na universidade obedecer aos imperativos da produtividade, pode tornar-se mera mercadoria/produto.

\subsection{A diferença entre produtividade e produção do saber e seus mo- delos de concepção universitá ria}

É inconteste que a ênfase da política governamental brasileira na avaliação institucional das Instituições Federais de Ensino Superior tem sido sobre sua eficiência/produtividade, em detrimento da crítica reflexiva e da produ ção do con hecimento. No bojo dessa ótica, o ensino superior é visto não como um investimento do Estado, mas como um gasto, uma mercadoria de qualidade de interesse privado. Em conseqüência, deve ser paga não pelo fundo público, mas pelos alunos e pelas empresas nacionais e multinacionais.

Entretanto, é mister elucidar o equívoco de tal postura. É imperioso que se afirme de antemão que "produtividade não equivale à produção, nem necessariamente à produção de qualidade" (CARDOSO, 1994, p. 38). A substituição da idéia de produtividade pela idéia de produção do saber é benfazeja porque a lógica da universidade pública (portanto, do conhecimento aí produzido) é diferente da lógica empresarial. O tempo do conhecimento é distinto do tempo do produto; como também o alcance do conhecimento igualmente é infinitamente superior ao do produto, visto que aquele depende de necessidades vitais, enquanto este se regula exclusivamente pelas leis do consumo mercadológico.

No âmbito do modelo da produtividade, "a preocupação com o conhecimento é a reafirmação do valor econômico desse conhecimento entendido como força de produção" (DIAS SOBRINHO, 1999b, p. 152), denotando sua funcionalidade e transformação efetiva em capital humano. Estimula-se a "transferência do conhecimento para a estrutura econômica" (p. 159), provocando a despolitização da universidade. Busca-se a objetividade do conhecimento por meio de sua neutralização sócio-política. Contudo, como se sabe, nenhum conhecimento é neutro, mas condicionado ideologicamente.

Reunindo as análises de CHAUÍ (1999a) e CARDOSO (1994), constata-se que a produtividade - categoria proveniente do modelo empresarial e transferida à universidade, refere-se aos critérios quantitativos de gestão interna universitária, entendendo-a como organização (importa aí o planejamento, a previsão, o sucesso). Assim concebida, a universidade utiliza-se da prática instrumental, estratégica, sem questionamento de sua função, existência ou seu papel na sociedade; ao contrário, importa-lhe empregar os meios adequados cujos fins são a eficiência e até mesmo o sucesso.

Entretanto, a categoria produção do conhecimen to (CARDOSO, 1994; VELLOSO, 1989) está atrelada à concepção de universidade enquanto institui- 
ção social (seu ideário básico é a formação, a reflexão, a criação e a crítica). Assim sendo, sua legitimidade não é apenas interna, mas também pública e social. Caracteriza-se pela autonomia do saber diante das práticas sociais e tem na democracia um sustentáculo inalienável, enquanto que o saber, embora autônomo, é direito de todos.

A instituição tem como referência a sociedade, enquanto que a organização é auto-referente. A primeira deseja responder às contradições impostas pela divisão social, enquanto que a segunda tem como alvo não a resposta às contradições, mas vencer a competitividade. Ora, sabe-se que o saber produzido não é indiferente ao seu lugar social, sendo este a condição de possibilidade daquele. ${ }^{1}$ Não há conhecimento universitário que não tenha como origem e referência 0 aspecto societário.

Não obstante, a passagem do modelo universitário baseado na produção de conhecimento para aquele baseado na produtividade não é aleatória. Sua determinação situa-se na mudança de um projeto de sociedade baseado num modelo democrático para o novo modelo neoliberal. Tal modelo impõe uma nova concepção de produção, de vida, de pensamento e até mesmo de sentimentos, por meio de uma falácia ideológica cujo fim é a produção ou reprodução do capital.

Encarregada de globalizar essa ótica, a política dos organismos multilaterais (BANCO MUNDIAL/BIRD, BID) entende a eficiência universitária só enquanto redução dos investimentos governamentais para as Instituições Federais de Ensino Superior e captação de recursos junto ao setor privado.

O discurso da produtividade está também atrelado ao imperativo da modernização (LMA \& AFONSO, 1993, p. 33-49) e da racionalização empresarial. Para CARDOSO (1994, p. 5), a política educacional para a universidade tem como pressuposto uma pretensa concepção "modernizadora, racionalizadora, integrada com a atividade produtiva". Desde o final dos anos 50, a política para o ensino superior brasileiro tem sido sempre setorial, condicionada aos imperativos econômicos: na sociedade dos anos cinqüenta, o ensino superior brasileiro estava circunscrito ao projeto desenvolvimentista do país. Esse vínculo continuou, embora com outra conotação e outro significado, na "ditadura militar e [foi] mantido - pelas mesmas forças sociais e em alguns casos pelas mesmas pessoas - pelos governos da chamada 'transição democrática"' (CARDOSO, 1994, p. 3). Já nos anos noventa, a política para o ensino superior encontra-se vinculada ao ajuste estrutural da economia e à competitividade do mercado internacional.

O discurso da adequação da universidade ao ajuste econômico concentra-se no âmbito da produtividade e da competitividade. Segundo ENGUITA (1996, p. 105): “Este deslocamento não tem nada de inocente, pois, enquanto o desenvolvimento é o objetivo dos países pobres, a competitividade o é dos países ricos". Portanto, os objetivos da política para o ensino superior têm 
estado voltados para o fortalecimento dos países centrais e não propriamente dos países periféricos.

\subsection{OS limites da ava lia ção docente no interior do modelo da produ- tividade}

Um dos critérios do pensamento neoliberal que mais tem influenciado na avaliação institucional é a avaliação docente. Esta tem se concentrado na análise da qualificação do docente por sua titulação, pelo número de artigos publicados, pela participação em simpósios, congressos, etc. Nesse sentido, não interessa principalmente a qualidade da sua publicação, mas a quantidade de publicações. Esse modelo reforça o individualismo acadêmico e a competição, fomentando a exclusão e as desigualdades. Seguindo CHAUí (1999a), ao colocar como pedestal o sucesso , o compromisso social do docente torna-se irrelevante diante do seu compromisso individual; sua prática social torna-se insignificante diante dos seus ganhos individuais significativos. Essa postura meritocrática, própria da teoria do capital humano, tem como pressuposto a exaltação do indivíduo em detrimento do coletivo, da quantidade em detrimento da qualidade. Porém, é mister ressaltar que a sociedade não é o produto dos indivíduos, mas são os indivíduos que se produzem no interior das relações sociais.

Imiscuídos nesse cenário, os docentes fazem parte do processo de racionalização como "empreiteiros acadêmicos" (CARDOSO, 1994, p. 5). Sua atividade depende da "competitividade" e, portanto, da luta mesquinha do capital contra o trabalho (p. 23). No contraponto da história, o docente é 0 trânsito, o veículo pelo qual a elitização social se reproduz e se sedimenta de modo racional. Por conseguinte, no interior da reorganização capitalista, seu trabalho deixa de ser autônomo, tornando-se dependente das relações desiguais da reprodução e acumulação do capital e da maximização do lucro.

As políticas educacionais do governo Cardoso para as Instituições Federais de Ensino Superior têm se manifestado na emergência da avaliação universitária segundo critérios de eficiência/produtividade. Visto que a avaliação docente faz parte da avaliação institucional, a tendência da preocupação do docente universitário tem se deslocado da produção do saber (da crítica, da reflexão, da formação e da criação) para a eficiência/produtividade (publicações curtas e numerosas sem densidade científica, busca de citações por outros autores, etc.). A partir do modelo emergente, a avaliação docente encontra-se direcionada unilateralmente para a competên cia, entendida como produtividade do trabalho acadêmico. Nessa perspectiva, sob a ótica do capital, controla-se a produção universitária por meio da relação não sempre equânime entre avaliação docente e destinação de verbas (CARDOSO, 1994, p. 24). 
A docência no imperativo da racionalização torna-se técnica, pragmática e burocrática, quando sua função seria criar espaços para o exercício da crítica e do aprofundamento dos problemas. Assim concebida, "a docência compromete a produção do saber" (LBAANEO, 1998, p. 34).

Segundo CARDOSO (1994), o docente situa-se num contexto estrutural universitário eminentemente hierárquico e diferenciador. "Diferencia ensino e pesquisa, em detrimento do ensino, diferencia graduação e pós-graduação, em detrimento da graduação. Conseqüentemente, produz uma hierarquização no próprio interior do corpo docente." (p. 33). Diante da subordinação da política educacional do ensino superior à política de ciência e tecnologia, cujo caráter é privatista, o educador identifica-se com a pesquisa; ao provocar uma dicotomia entre ensino e pesquisa, supervalorizando esta última, o ensino passa a ser visto como uma atividade inferior que rouba 0 tempo para a pesquisa.

Para evitar qualquer unilateralidade, deve-se, por outro lado, entrever como as pesquisas são avaliadas. No âmbito da ótica neoliberal da produtividade, a pesquisa universitária passa a ser avaliada enquanto mercadoria, enquanto produto quantificável, mensurável, determinado pela relação custotempo-benefício (enquanto valor de troca).

Por isso, as pesquisas mais financiadas situam-se no âmbito da ciência e tecnologia, visto que podem ser quantificadas e mensuradas. Ademais, valoriza-se a pesquisa que apresenta a racionalização dos custos, a execução a curto prazo e um alto potencial de rentabilidade empresarial. A política de investimentos desloca a atividade da docência para a da pesquisa (lucrativa). Esta, por sua vez, perde sua pertinência, visto que é considerada um valor de troca (considerada neutra, não reflexiva) a serviço da reprodução do capital internacional.

Considerando que a produtividade tem como critério a tríade custotempo-benefício, as pesquisas deixam de ser aprofundadas para que seus resultados sejam alcançados no prazo previsto pelo projeto, geralmente não muito longo. Conforme CARDOSO (1994, p. 36), "é preciso publicar, mas publicar sempre e continuamente". Com isso, a elaboração de temas profundos cede lugar a um critério quantitativo dado pela insaciável publicação de artigos e resenhas; prioriza-se a publicação coletiva desde que os autores se citem mutuamente, mesmo que não produzam coletivamente.

A concepção de pesquisa circunscrita ao âmbito empresarial produtivista torna-se auto-referente, pois são citados somente os membros de determinado grupo de pesquisa, ou de determinada universidade. Ao ignorar outras publicações, preocupando-se exclusivamente com o desempenho e com a produtividade, prescinde-se também do desenvolvimento científico e da produção do saber. A produtividade, pois, está ligada à busca do sucesso na carreira, comprometendo-se com aqueles requisitos que rendem na pontu- 
ação dos processos avaliativos. A conseqüência imediata consiste na prática de uma ética excludente e concorrencial em que "é preciso excluir ou rebaixar os demais para melhorar, ou pelo menos manter sua posição no sistema" (CARDOSO, 1994, p. 38). Dessa forma, os valores se deslocam do social para o individual. A ética da exclusão e da desigualdade implica um comportamento anti-ético.

CHAUÍ (1999a) analisa o modelo de universidade por ela chamado operacional e situa essa problemática como a "heteronomia da universidade autônoma”. Ou seja, o modelo da produtividade está estreitamente ligado a uma universidade que só opera, mas não age, pois na realidade não sabe 0 seu rumo. É importante ressaltar que a atividade do docente, ao dissociar o ensino da pesquisa, estimula uma dupla deterioração: a docência é pensada como uma habilitação rápida para graduados que precisam entrar rapidamente num mercado de trabalho do qual serão expurgados em poucos anos; ou ainda, como a mera transmissão de pesquisas para novos pesquisadores (CHAUÍ, 1999a). A formação, assim, cede lugar para a transmissão e o adestramento.

A pesquisa é deslocada de seu eixo qualitativo. O conhecimento baseado na produtividade não muda a realidade, reduzindo-se simplesmente a um jogo de linguagem e de pensamento. A pesquisa se reduz a uma "estratégia de intervenção e de controle de meios ou instrumentos para a consecução de um objetivo delimitado" (CHAUí, 1999a, p. 38); deixa de ser a busca do conhecimento de algo, para limitar-se à posse de instrumentos para intervir e controlar alguma coisa. Rompe-se, pois, com a idéia da docência (ensino) aliada à pesquisa qualificada.

\subsection{A insuficiência da qualidade total medida pela eficiência/produ- tivida de}

Como romper com a unilateralidade economicista da teoria do capital humano e sua reformulação neoliberal presente na política educacional do governo de Cardoso em relação às Instituições Federais de Ensino Superior? Quiçá uma alternativa viável seria, por um lado, desvincular a idéia da qualidade e do saber universitário do paradigma da nova roupagem da teoria do capital humano: a qualidade (total) medida pela eficiência/produtividade. Usando a linguagem marxiana: evitar que a qualidade das Instituições Federais de Ensino Superior seja medida apenas como se fosse uma mercadoria, um valor de troca (relação tempo-custo-benefício); por outro lado, destacar a especificidade do tempo do conhecimento como distinto do tempo da mercadoria; destacar a especificidade dos objetivos do conhecimento (utilidade social), que devem ir além dos objetivos da mercadoria (consumo). Enfim, devese recuperar o valor de uso próprio do conhecimento e sua utilidade para a vida. Isso possibilita entender a educação e o conhecimento a partir de sua 
especificidade, qual seja, investigar algo que exige reflexão, crítica, invenção, criação; pensar e dizer o que ainda não foi pensado nem dito; agir e não apenas operar ou executar.

\section{A proposição da produção do saber e da qualidade só- cio-política}

A produção do saber é uma categoria que permite compreender a educação superior pública no âmbito do trabalho, e não da mercadoria; 0 papel docente, de mero transmissor de conhecimentos, para um modelo gerador de consciência; e o papel da universidade, de mera empresa produtivista para uma instituição comprometida com a sociedade democrática na construção do conhecimento.

Para isso, é imprescindível deixar de entender o conhecimento como uma força produtiva direta imposta como uma força externa do mercado sobre a pessoa (SANTOS, 1998, p. 17). Deve-se romper com a centralidade dos resultados e o império dos meios para encarar o labor universitário como tarefa de interpretação e modificação do mundo. Implica que cada cultura realize seu conhecimento do mundo a partir de sua realidade; que a universalidade como matriz de verdade não seja substituída pela globalização efêmera do conhecimento instrumentalizado e não ignore sua pertinência e qualidade sócio-política.

Ao tratar-se da qualidade (institucional universitária), é necessário um aprofundamento do conceito. Em primeiro lugar, contrariamente ao que apregoam os que submetem a educação às teorias organizacionais, o termo não tem uma característica universal, ou seja, não se pode uniformizar critérios de qualidade institucional universitária sem levar em consideração sua pertinência sócio-política.

A qualidade entendida como função política vinculada a um projeto educacional representativo de uma nova política de ensino que expresse o posicionamento da universidade na efetivação de suas funções, diante do momento histórico da sociedade em que se insere não se constitui em atributo universal, assim como a melhoria da qualidade de ensino que se reclama não pode ser entendida como algo neutro e atemporal uma vez que está em função de uma sociedade que é alterável e varia de época para época e de lugar para lugar (UFPR, p. 26).

A qualidade reveste-se da especificidade histórica de cada contexto. Tal pertinência foge da perspectiva empresarial do modelo da qualidade universitária medida pela eficiência/produtividade (racionalização, otimização). Conforme a perspectiva dualizante imposta pelo GERES já em 1985, a universidade eficiente e produtiva é identificada como universidade de conhecimen- 
to (CARDOSO, 1991, p. 18). Esse atributo está reservado para algumas universidades federais que se constituem em verdadeiros centros de excelência de desenvolvimento de ciência e tecnologia. A produtividade universitária identifica-se e se encontra subordinada ao modelo de produtividade empresarial. Esse suposto modelo empresarial e modernizador fundamenta-se em teorias organizacionais de caráter neotayloriano, que entendem a universidade não como uma instituição, mas como uma Organização Social. Seguindo LMA \& AFONSO (1993, p. 38), "Convoca-se uma monorracionalidade de tipo técnico e uma perspectiva gestionária-utilitária (neotayloriana), decompõe-se e fragmenta-se o processo de avaliação quantificando, mensurando, formalizando; adota-se uma visão mecanicista da organização escolar, centrada nas operações técnicas, na eficácia e na eficiência".

Na verdade, a influência da Filosofia e Pedagogia da Qualidade Total na avaliação externa das universidades federais reflete a continuidade histórica do tecnicismo positivista já presente na Lei 5.540/68. A idéia de que a universidade deve ser uma "empresa privada" e não uma "repartição pública" já era proposta por Acton em 1966 (ACTON, 1966, p. 87). ${ }^{1}$

Portanto, a monorracionalidade tecnicista instrumental da década de 1990 já tinha seu gérmen no final da década de sessenta. A emergência dessa monorracionalidade organizacional e tecnocrática utiliza jargões como: "empresa, capacidade, competência, racionalização, eficácia, controle de qualidade, etc." (SGUISSARDI, 1997, p. 57) (grifos do autor). Desprovidos de conteúdo sócio-político, os problemas da instituição universitária são tratados somente como problemas técnicos, neutros, objetivos e homogêneos próprios da gestão administrativa.

No entanto, a idéia de qualidade subjacente às propostas de avaliação institucional das Instituições Federais de Ensino Superior brasileiras dos anos noventa está estreitamente vinculada às orientações do Banco Mundial e à visão dos países centrais.

O conceito de qualidade total está estreitamente subordinado à racionalidade econômica. Transposto para a universidade, neutraliza-se sua função política em nome da funcionalidade do conhecimento. A tecnologização da sociedade, por sua vez, apresenta-se como a solução para os problemas políticos, morais e sociais. Nesse sentido, o conhecimento atrelado à ótica do capital caracteriza-se pela sua objetividade, neutralidade e funcionalidade. Por isso, o conhecimento universitário é avaliado independentemente das relações subjetivas próprias da vida societária.

Segundo DIAS SOBRINHO (1999b, p.160), “A tríade qualidade-produtividade-rentabilidade, no mundo empresarial, é destituída de qualquer noção ético-filosófica". O autor constata que "O Banco Mundial tem incentivado os governos a realizarem esse tipo de 'avaliação de qualidade', que no caso corresponde à mensuração e controle da eficiência custo-benefício em educa- 
ção. (...) É preciso que os sistemas universitários se esforcem para obterem maior eficiência e respostas às demandas do mercado, com o mínimo desperdício e o menor custo possível" (p. 161).

Porquanto não há produção humana que não seja enraizada em terreno social e porque não se reduz a um conjunto de técnicas, toda produção humana tem uma raiz social e não meramente técnica e supõe um debate ético e político. A qualidade, por sua vez, implica que "a universidade deve estar duplamente comprometida, tanto com sua história e sua autonomia, quanto com sua função social de desenvolvimento e de formação da mais ampla cidadania participativa" (DIAS SOBRINHO, 1999b, p. 150).

Nos anos noventa, as Instituições Federais de Ensino Superior têm sofrido muita pressão social e política, provocando um acréscimo dos encargos governamentais. Isso gerou alguns efeitos: insuficiência crescente de recursos orçamentais destinados às instituições de ensino superior públicas; expansão de matrículas no mercado crescente das escolas privadas, muitas delas de baixa qualidade; instituições de ensino superior heterogêneas e desiguais, fragmentando-se a imagem social de organizações com identidade própria.

Para SANTOS (1994, p. 186), o crescimento orçamentário desestabilizou as relações de saber e de poder, no interior das universidades, que cada vez mais são compelidas a buscar no setor produtivo os recursos alternativos para sua sobrevivência, submetendo-se crescentemente a critérios que lhes são estranhos e desfavoráveis.

A ausência do Estado das políticas públicas tem enormes conseqüências para a avaliação, que "corresponde mais à prestação de contas da gestão universitária, da administração financeira, da eficiência da universidade em apresentar os produtos requeridos, e a busca de comprovações da seriedade institucional de recursos para a produção e o desenvolvimento do capital intelectual, que passa a ser disputado como o mais importante instrumento do desenvolvimento econômico" (DIAS SOBRINHO, 1999b, p. 152-153).

Ao pretender romper com os moldes da qualidade total e da produtividade, não se deseja contrapor a uma avaliação técnica e objetiva. $\mathrm{O}$ questionável, em primeiro lugar, é a identificação da objetividade com a neutralidade; em segundo lugar, que essa seja a única forma de avaliação, ou uma ação imposta de cima para baixo sem levar em conta a heterogeneidade das Instituições Federais de Ensino Superior. De igual forma, não se pretende opor-se à ciência e à tecnologia, mas buscar alternativas viáveis para sua politização.

As limitações próprias da avaliação institucional a partir da Pedagogia e Filosofia da Qualidade total e da eficiência/produtividade são bem precisas: em primeiro lugar, questiona-se a utilização de informações simples e rápidas, avaliando unicamente produtos e resultados, ignorando as significações dos processos. No entanto, a universidade e a produção do conhecimen- 
to constituem um processo complexo. Sua avaliação não deve limitar-se a verificar se os objetivos foram ou não alcançados, mas "deve procurar interpretar os significados desses objetivos em relação aos princípios e propósitos fundamentais de uma instituição concreta em particular" (DIAS SOBRINHO, 1999a, p. 68). O outro limite constatado na avaliação institucional do governo deve-se ao seu caráter externo. Ou seja, mesmo que as avaliações sejam feitas internamente, é ineludível sua comparabilidade com outros modelos e, inevitavelmente, a produção de uma hierarquização. Para SANTOS (1997, p. 215), "Mesmo que seja efectuada pela própria universidade, tal avaliação será sempre externa, quer porque coloca a utilidade social da universidade num conjunto mais amplo de utilidades sociais, quer porque envolve, mesmo que implicitamente, uma comparação entre modelos institucionais e seus desempenhos". Com isso, instaura-se a competição entre as instituições públicas; entretanto, a competição é uma prerrogativa do setor privado.

É claro que as universidades devem ser eficientes, competentes, responsáveis no uso de seus recursos. Porém, a lógica da universidade pública deve ser diferen te daquela da doutrina economicista. A universidade pública é eficiente não pelo lucro alcançado, mas pelo sentido ético de sua função social. A competência exige qualidade científica, mas que seja de relevância social, proporcionando maior eqüidade e enraizamento histórico.

Segundo DIAS SOBRINHO (1999a, p. 69), "Uma avaliação que produz a competitividade de acordo com as leis da selva ou do darwinismo social e fortalece o entendimento da educação como um elemento do mercado acaba retirando da universidade a sua inalienável prerrogativa da crítica".

Ora, a universidade como instância crítica da sociedade deve ter um certo distanciamento para que proponha alternativas de mudança social. Não sendo assim, o regulador da vida social passa a ser o mercado, que, como se sabe, busca evitar a crítica, o debate, a busca da construção da comunidade.

A referência da universidade não deve ser exclusivamente o mercado e os setores privilegiados pela organização economicista, mas as demandas de toda a sociedade. Isto significa prescindir unicamente do valor do lucro e maximizar a eqüidade, buscando dirimir as desigualdades e favorecendo os setores mais carentes. Conforme DIAS SOBRINHO (1999a, p. 70), a universidade deve lutar para minimizar a tendência do surgimento de uma bipolaridade: "o cidadão incluído no mercado globalizado do trabalho e do conhecimento e o indivíduo marginalizado e excluído de qualquer condição de competir por emprego e por uma vida minimamente digna" .

Por isso, é fundamental que a idéia de qualidade universitária rompa com o modelo produtivista/ eficientista e seja encarada a partir de uma postura dialética; ou seja, como produção e transmissão do saber e da cultura socialmente comprometidos. Do ponto de vista dialético, o saber é considerado trabalho (força de produção, segundo Marx) porque está em constante cons- 
trução; não se reduz à realidade dada, mas admite o conflito e a contradição. É a compreensão do mundo como construção e constante mudança.

Destarte, a universidade deve lutar pela qualidade sócio-política, visto que na sua origem subjaz a vocação política. Segundo CHAUÍ (1993, p. 11), "a vocação política teve prioridade na criação das universidades públicas e privadas no Brasil". Compreenda-se bem que, quando se fala em vocação política, não significa que a universidade deve limitar-se a seguir as políticas estatais, sejam neoliberais ou de índole socializante. Para a autora, a vocação política refere-se à elaboração de um projeto político "proposto pela própria universidade, pelo qual se definam modos de inserção da universidade no campo político e não tanto nos projetos que o Estado teve na criação das universidades" (p. 12).

Não obstante, por que atualmente ignora-se a vocação ou qualidade sócio-política da universidade no Brasil? Quiçá porque a proposição da qualidade sócio-política universitária implica a construção de um saber instituinte e não exatamente um conhecimento já instituído próprio da perspectiva do discurso da qualidade total; enfatiza o processo do conhecimento e não o conhecimento como produto.

Deve-se conceber o conhecimento e a realidade como dinamicidade e não como algo materialmente dado. 0 mundo da realidade universitária é instituinte, continuamente repensado e reconstruído; não se pode pois medilo como um produto ou uma mercadoria. A produção do saber universitário deve ter uma referência individual (autonomia de pensamento), mas também social (a prática produtiva tem uma natureza coletiva). Contudo, precede a referência social, visto que o social não é um produto dos indivíduos, mas inversamente.

Assim sendo, ao enfatizar a qualidade sócio-política, garante-se a institucionalidade universitária e sua formação constitutiva originária. Pensar a universidade só enquanto qualidade total (enquanto categoria própria do modelo empresarial) significa reduzir o conhecimento ao materialmente dado; reduzir os problemas educacionais a problemas de gestão; enfim, renunciar à institucionalidade universitária, entendendo-a como empresa e como organização operativa.

Por isso, o desafio em termos de política educacional para as Instituições Federais de Ensino Superior consiste em resistir diante do modelo neoliberal. Isso implica superar o modelo de qualidade universitária enquanto qualidade total e eficiência/produtividade. Deve-se reconhecer que o desenvolvimento educacional não se reduz a sua adequação à racionalidade econômica, mas implica um debate estrutural sobre a vinculação entre o político e 0 pedagógico (GIROUX, 1997), entre a qualidade e a cidadania, entre a produção do saber e a capacidade de pesquisa no âmbito das Instituições Federais de Ensino Superior. Se for reconhecido o papel sócio-político de tais Instituições 
na qualificação profissional e na pesquisa de ponta, talvez possa-se entender que o dinheiro público aplicado na sua manutenção e desenvolvimento não se reduz a mero gasto (que onera a poupança pública), mas, sobretudo, num investimento social que só trará benefícios para o país em todos os aspectos.

\section{Notas bibliográficas}

1 O GERES foi criado como um grupo interno do MEC pela Portaria no 100 de 6 de fevereiro de 1986; instalou-se pela Portaria no 170 de 3 de março de 1986, apresentando seus resultados em 1986 (CARDOSO, 1989b, p. 115).

2 Essas avaliações estavam associadas à campanha em Defesa da Escola Pública oriunda de vários setores acadêmicos. Entretanto, sobressaíram as comissões de Alto Nível nomeadas pelo Executivo, cuja lógica da eficiência, associada à idéia de modernização na reformulação da universidade, nortearam toda a questão da avaliação. (CARDOSO, 1989b, p. 117).

3 Aqui situa-se a pertinência universitária, ou seja, a idéia de que a universidade tem um enraizamento social e deve ser entendida no seu contexto histórico-social. Nesse sentido, quando se fala em Universidade Mundial do Banco Mundial (expressão irônica usada por SGUISSARDI, 1998a, p. 226), rompese com a pertinência universitária e com sua função social.

4 Rudolph Acton era assessor da USAID no Brasil. Passou pelo MEC e pelo CRUB (Conselho de Reitores das Universidades Brasileiras). Sendo membro executivo do CRUB, propunha que a Universidade não deveria pertencer ao Poder Executivo estatal. Esta deveria ter completa autonomia financeira e ser administrada como uma empresa privada.

\section{Referências bibliográficas}

ACTON, R. P. Rumo à reformulação estrutural da universidade brasileira. Rio de Janeiro: MEC/SESU, 1966.

AMORIM, Antônio. Avaliação institucional da universidade. São Paulo: Cortez, 1992.

BELLONI, I. Universidade: a busca de uma estratégia de transformação. Em Aberto, [s. l.], n. 10, p. 1-9, 1982.

BRASIL Leis, decretos etc. Decreto-lei no 9.131, de 24 de novembro de 1995. Diário Oficial da União, Brasília, 25 nov. 1995.

BRASIL Secretaria de Ensino Superior. Programa de avaliação institucional das universidades brasileiras. Brasília, 1994.

CARDOSO, I. A avaliação acadêmica e as fundações. Cadernos ANDES, Juiz de Fora, n. 7, p. 7-35, fev. 1989a. 
CARDOSO, I. A modernização da universidade brasileira e a questão da avaliação. In: MARTINS, C. B. (Org.). Ensino superior brasileiro: transformações e perspectivas. São Paulo: Brasiliense, 1989b.

CARDOSO, M. L A avaliação da universidade: concepções e perspectivas. Universidade e Sociedade, Brasília, v. 1, p. 14-24, set. 1991.

CARDOSO, M. L A ética e a construção do conhecimento : versão preliminar. Caxambú: ANPED, 1994.

CHAUÍ, Marilena de Souza. Entrevista explosiva. Caros Amigos, São Paulo, n. 29, ago. 1999a.

CHAUÍ, Marilena de Souza. A universidade em ruínas. In: TRINDADE, $H$. (Org.). Universidade em ruínas: na república dos professores. Petrópolis, RJ : Vozes, 1999b.

CHAUÍ, Marilena de Souza. A vocação política e a vocação científica da universidade. Educação Brasileira, v. 15, n. 31, p. 11-26, jul./dez. 1993.

DIAS SOBRINHO, José. Avaliação e privatização do ensino superior. In: TRINDADE, H. (Org.). Universidade em ruínas: na república dos professores. Petrópolis, RJ : Vozes, 1999a.

DIAS SOBRINHO, José. Concepção de universidade e de avaliação institucional. In: TRINDADE, H. (Org.). Universidade em ruínas: na república dos professores. Petrópolis, RJ: Vozes, 1999b.

ENGUITA, Mariano F. O discurso da qualidade e a qualidade do discurso. In: GENTILI, Pablo A. A.; SILVA, Tomaz Tadeu da. Neoliberalismo, qualidade total e educação: visões críticas. 4. ed. Petrópolis, RJ : Vozes, 1996.

FORUM PARANAENSE DE DEFESA DA ESCOLA PÚBLICA GRATUITA E UNIVERSAL Lei de Diretrizes e Bases da Educação Nacional: Lei 9394/96. Curitiba: APP: CUT: CNTE, 1997.

GIROUX, Henry. Os professores como intelectuais. Porto Alegre: Artes médicas, 1997.

LBANEO, José Carlos. Adeus professor, adeus professora?: Novas exigências educacionais e profissão docente. São Paulo : Cortez, 1998.

LIMA, L C.; AFONSO, A. J. A emergência de políticas de racionalização: de avaliação e de controle da qualidade na reforma educativa em Portugal. Educação \& Sociedade, Campinas, n. 44, p. 33-49, abr. 1993.

MOROSINI, M. C.; LEITE, D. B. C. Avaliação institucional como um organizador qualificado: na prática, é possível repensar a universidade? In: SGUISSARDI, 
V. (Org.). Avaliação universitária em questão: reformas do Estado e da educação superior. Campinas, SP: Autores Associados, 1997.

RISTOFF, D. I. Princípios do Programa de Avaliação Institucional. In: BRASIL. Secretaria de Ensino Superior. Programa de Avaliação Institucional das Universidades Brasileiras. Brasília: SESu, 1994.

SANTOS, Boaventura de Souza. Pela mão de Alice: o social e o político na pós-modernidade. 2. ed. São Paulo: Cortez, 1996.

SANTOS, Boaventura de Souza. Pela mão de Alice: o social e o político na pós-modernidade. 3. ed. [S. l. : s. n.], 1997.

SANTOS, Milton. Ser intelectual na era da globalização. In: ENCONTRO NACIONAL DE DIDÁTICA E PRÁTICA DE ENSINO (1998 : Águas de Lindóia, SP). Anais do ... [S. l. : S. n. 1998].

SGUISSARDI, V. Autonomia universitária e mudanças no ensino superior: da polissemia do conceito às contradições de sua aplicação. In: CATANI, A. M. (Org.). Novas perspectivas nas políticas de educação superior na América Latina no limiar do século XXI. Campinas, SP: Autores Associados, 1998a.

SGUISSARDI, V. Políticas de Estado e políticas de educação superior no Brasil : alguns sinais marcantes da dependência. In: MOROSINI, M. C. (Org.). MERCOSUL/MERCOSUR: políticas e ações universitánias. Campinas, SP: Autores Associados; Porto Alegre, RS: Editora da Universidade, 1998b.

SGUISSARDI, V. Para avaliar propostas de avaliação do ensino superior. In: SGUISSARDI, V. (Org.). Avaliação universitária em questão: reformas do estado e da educação superior. Campinas, SP: Autores Associados, 1997. (Coleção Educação contemporânea).

UNIVERSIDADE FEDERAL DO PARANÁ. Comissão de Avaliação da UFPR. Diretrizes para a avaliação da UFPR. In: ZAINKO, M. A. S.; PINTO, M. L. A. T. Avaliação institucional: a trajetória de uma década: 1987- 1997. Curitiba : UFPR, 1998.

VELLOSO, Jacques. Universidade e seu financiamento: ensino público e privado na Constituinte. In: FÁVERO, M. L. (Org.). A universidade em questão. São Paulo: Cortez: Autores Associados, 1989. (Coleção Polêmicas do nosso tempo; 29).

e-mail: educacao@rla13.pucpr.br 